\title{
Tourism Industry must benefit from IT\&C Hyperautomation
}

\author{
Vasile MAZILESCU ${ }^{\star}$
}

\begin{tabular}{l} 
A R T I C L E I N F O \\
\hline Article history: \\
Accepted March 2021 \\
Available online April 2021 \\
\hline JEL Classification \\
L83, Z30, C88 \\
Keywords: \\
Tourism Process Automation \\
(TPA), Digital Tourism, Ubiquitous \\
Intelligence, Cloud Computing
\end{tabular}

Information technology has always played a key role in the development of the tourism industry. Booking systems (CRS) and global distribution systems (GDS) have been developed, first by airlines and then by hotel companies, to provide travel agencies with access to valuable programs and information and to request customer bookings. The Internet has had an extraordinary transformative effect on communication technology and the tourism industry. At Amadeus, technology is intended to improve travel. The airport is a focal point for even the most frequented travelers. Self-service check-in, biometric passports, facial recognition, pre-authorization and queue management are specific examples of how technology is starting to make things better for people. Online bookings and payment options are used by more and more travel providers and consumers and have led in the case of tourism as one of the most important categories of ecommerce. Consumers were offered several options and gained easy access to information about different products. E-tickets are a direct result of e-commerce and have greatly simplified travel, similar trends have not led to the new e-tourism and e-tourism. The convergence of information and communication technologies effectively integrates the full range of hardware, software, groupware and blurs the boundaries between equipment and software, between technology and people [11,21]. Wireless networks are widely used for communications, networking of equipment, and interoperability between organizations and functions. Digital information systems have evolved from simple interconnected components working together to collect, process, store, and disseminate information to dynamic, interoperable mechanisms for collecting, processing and disseminating information within organizations and their environment [6]. Tourism is the fourth largest export category in the EU and brings collateral benefits to the European economy as a whole. Tourism is a complex ecosystem that includes many actors: providers of information and services offline and online (tourist offices, digital platforms, travel technology providers), travel agencies and tour operators, accommodation service providers, management organizations of destinations, tourist attractions and passenger transport activities. Tourism and transport are also based on major industrial sectors (construction, aircraft manufacturing, ship building). Large multinational corporations operate with small businesses, $90 \%$ of which are represented by SMEs. Tourism is present in different types of areas and regions: urban centers, island, coastal, rural, remote and outermost regions.

This paper consists of an Introduction to the analyzed issues, from Section 2 which defines and characterizes briefly the extensive process, but extremely efficient, regarding the hyper automation of

\begin{abstract}
The tourism industry is one of the most significant users of Internet technology, an variety of ways and leads to fundamental changes in the structures of the tourism industry in the context of the new era of digital travel. The Covid19 pandemic has fundamentally changed the way we travel. It is essential in this context that companies in the hospitality innovation are essential for the development of new business models, and there is a growing need for staff with well-defined digital skills. This fully applies to the tourism
sector, companies in this industry must invest in staff, to provide opportunities for changing mentalities and work paradigms. This paper analyzes and emphasizes the urgent of language or visuals, accompanied by a massive migration to the cloud, are just some of
\end{abstract} (C) 2021 EAI. All rights reserved. 西 
business processes in the field of tourism, Section 3 focused primarily on the basic aspects of digitization activities in the tourism industry. Section 4 presents a technological mix that we consider extremely current in order to achieve TPA. The conclusions are only a part of the possible directions of implementation of some technologies, adapted to a series of requirements and restrictions. It must be checked whether there is a direct relationship between the level of investment in IT structures and the final quality of guest services. Innovations in digital services are essential for the competitiveness and modernization of the tourism business, for stabilizing revenues and increasing customer satisfaction.

\section{Literature review}

Online travel agencies (OTAs) play a crucial role in the recovery process, in which SMEs can capitalize on and digitize their data to adapt and build long-term resilience. SMEs use OTA digital platforms to accelerate the recovery of technological and economic gaps. There is a change in the dynamics of the relationship between SMEs and OTA, the latter being increasingly recognized and appreciated as a technology, data and marketing partner. It is vital for hospitality service providers for SMEs to understand trends and reach a new target audience. SMEs using OTAs can reduce their investments, especially in terms of payment functions, customer support, and marketing efforts. OTAs have also expanded opportunities to diversify destinations, helping to stimulate tourism in cities. The use of statistical data will demonstrate to SMEs in the future that OTAs are well-positioned technology partners, in order to provide SMEs with a comprehensive understanding of large volumes of data and to improve their business [19]. Statistical data can be used to optimize revenue through meta-search, machine learning, artificial intelligence (AI), product diversification and platform centralization. OTA now uses AI technology to tailor offerings to customers. This will allow SMEs to personalize products and services with high-potential consumers and make a better profit [38]. SMEs call on governments to work with OTAs to stimulate post-COVID travel recovery [15]. In this crucial period of recovery, greater public-private partnership will increase confidence in travel, in which local governments can rely on private sector trade expertise to identify and create new opportunities to improve industry, business and lives. affected by COVID, as well as to remain relevant in the changing economic environment [27, 36]. Successful hoteliers use smart data and technologies to optimize pricing and marketing [7]. More and more tourism companies are unable to perform complex data analysis and global marketing. Due to its unique characteristics, blockchain technology can have an extraordinary impact on business processes and the entire tourism industry $[1,8,24]$. The development of sustainable tourism faces many challenges and barriers, such as high energy consumption and emissions, inadequate waste management and treatment, biodiversity loss and habitat destruction, threats to heritage management and cultural integrity, lack of communication channels and of information platforms. AI systems for natural language processing enrich two-way human-computer interactions with new contact relationships [31]. There is limited research on the phenomenon of voice-based digital assistants and their adoption by hotels to automate workflows and improve the guest experience [17, 29]. The benefits of applying voice-based digital assistants in hospitality outweigh the disadvantages for both hotels and guests. For hotels and other companies in the tourism industry, one of the most interesting uses of AI is to provide support to online customers, already being widely adopted in order to feed chatbots on social platforms as well as instant messaging applications [37 ]. Used in this way, $\mathrm{AI}$ is able to answer questions and provide valuable information to customers, even when a customer service representative is not available. Customers want faster and faster response times on online platforms, and AI allows companies to provide execution times that are impossible for people to achieve. The key advantage of AI in this area is its ability to quickly and accurately sort huge amounts of heterogeneous, semantically different data $[19,33]$. The human equivalent would take much longer and could contain more errors [14, 34]. This is also the case with facial recognition systems [4, 39].

The constituent components of IT\&C automation include AI, machine learning, the application of systems equipped with software that simulates human intelligence processes, including learning without explicit instructions. We can also include in this broad process of hyperautomation the processing of natural language, the use of robots that can operate using the Internet of Things (IoT) and other data to learn and make autonomous decisions, predictive analytics to estimate future results using statistical algorithms and machine learning. semantic web technologies $[3,5,12,16]$. Increasingly, interactions between consumers and companies are automated. Chatbots in the airline industry began as automated FAQ pages, a tool that could further enhance the efficiency of customer service teams by preparing a chatbot to identify and answer the most obvious questions. The landscape of chatbots is changing, and chatbots are able to learn much more. Connecting chatbot technology to internal data sources and layering in some machine learning systems allows robots to improve over time, learning more about how to best answer the questions they receive.

Governments play an important role in creating the right framework conditions for the digital transformation of tourism business models and the entire tourism ecosystem, based on TPA $[9,10,13]$. By using software technology, the TPA strategy leads to the reorganization of staff and systems through efficient workflows, eliminating the need to perform repetitive or low-level tasks on the part of employees. All these activities are left in the care of integrated applications. The process of automation based on different technological paradigms makes everyday things easier, faster and better and frees human beings from uncreative work. Some of the most impactful automation technologies in the automotive industry are being 
developed: automated vision, AI for autonomous machines, cognitive computing for IoT-connected machines and collaborative robots $[2,30]$. Automation has already been implemented in the manufacturing sector, especially in the form of Industry 4.0 technology. Production lines with robots that do most of the work have been a reality for a long time. TPA goes beyond traditional data management, through advanced software systems and programs that integrate many applications. Automation allows the company to maintain control over various processes, such as customer relations, predictive analytics, planning, sales, standardization and development $[23,35]$. The process can target both complicated information technology tasks, such as managing system users and resolving network problems, and programs such as e-mail marketing services. Enterprise software being a collection of customizable programs for the entire organization, requires specific business and computing knowledge in order to be implemented, being meant to serve the entire organization. Every day, employees schedule meetings, request approvals, review documents and workflows, route information, and search for status updates. In many companies, people still do these actions manually. This can be an extremely difficult struggle when you have to go through several email reviews, answers and searches to find the current version of a document. Business Process Automation (BPA) produces within the company the improvement of communication, minimizing costs through a more efficient allocation of resources, reducing the volume of consumables, eliminating manual errors, optimizing workflows, establishing a clear hierarchy of approval, maintaining a constant speed of the work process by reducing the time required to perform repetitive tasks [28]. More than half of companies' business processes can be automated. Each industry has different needs to automate specific business processes.

In order to automate as many processes as possible, companies are moving towards BPA principles to make them more efficient: i) in telecommunications, automate customer service, billing systems, databases, document / workflow management systems and support technical; ii) in trade and industrial production the CRM, ESB and ERP systems, the storage and acquisition activities, the production processes and the document flow management are automated; iii) in banking centers: automation of credit processes, credit and money transfers, integration with other automated banking systems, card systems and budget management, together with the development of front-and back-office systems. We find that the digital transformation may seem like an overwhelming goal for organizations that have not yet made significant strides toward this approach. BPA can be a cornerstone for adopting that culture of continuous transformation, being an essential element of any modern business, leading to increased efficiency and productivity. Integrated and coherent policies are needed to capitalize on TPA opportunities, while addressing the challenges and minimizing any negative consequences that may arise. A well-designed policy approach involves a mix of short- and long-term initiatives, which foster increased conditions for the use of digital technology, encourage the participation of SMEs by reducing barriers and increasing digitalization opportunities, encourage new ways of working, new management approaches and new digital cultures using intelligent automation, which incorporates recent advances in technology to manage and improve business processes automatically and continuously.

\section{Digital business management in the field of tourism}

In today's world of rapid technological innovation, customers demand integrated products and solutions that are always updated, complemented by the latest models and technologies. This shortens the established product life cycles and determines the demand, not only for frequent product updates and incremental improvements, but also for complete changes and innovative technological innovations. For industrial customers, "traditional" products often need to be digitally enhanced in a full range of ways, including adding applications, human-machine interfaces, remote access and monitoring, predictive maintenance, configuring adaptive self-learning parameters, services virtual assistance and other digital services that can be seamlessly integrated into existing and evolving comprehensive solution ecosystems. In addition, customers are increasingly demanding customized products and services tailored to their specific requirements. This creates challenges for developers and manufacturers who need to establish a modular product strategy that can be individually tailored to the specific features, projects, services and integrated solutions that customers demand. Without digitized product development processes, technical changes become too costly and time consuming. Customers expect their orders to be fulfilled instantly - with sameday delivery, now the new norm. In some industries, "on-time" delivery has already moved to "in-order" delivery, in which suppliers have to deliver their parts or components in a very short window, in the correct order. Leading companies also use digitally capable tools to better capture customer needs and to design integrated products and solutions that are individualized for specific customers, offering customers complete integrated solutions, rather than individual products and services. Effective co-design tools, common standards and simultaneous access to common product development platforms then become part of an integrated ecosystem. Customer requirements have always been an integral part of the product development process and the vast majority of companies say they work closely with customers to develop products and services. We have found that they are more likely to use data analytics and AI tools. To analyze customer data in order to optimize new or existing products and services. Data collected for analytical purposes may include consumer characteristics, data from online configurators, product usage patterns, information field quality 
and service data, or product performance and status information throughout the product life cycle. Transforming the business model with the support of digital technologies can be achieved by using two methods: hybridization and innovation. Hybridization is achieved by combining new business models with existing ones in one or more dimensions of the business model. Meanwhile, innovation is achieved through the development of a completely new business model. This is done by first defining the value proposition and then followed by designing other value dimensions. Traditional strategic planning methods cannot achieve the disruptive changes that result from digital technologies. This is because traditional planning does not include disruption caused by the non-linear nature of technological development. The dynamism, uncertainty and complexity of the business environment, including the disruptive change caused by the COVID-19 pandemic, can all be the major triggers doing the transformation to digital business models. Digital technologies can transform the core value offered to customers that make new business models more relevant to the emerging business environment. The characteristics of digital business models differ from the characteristics of the traditional model in which many of the activities can be reproduced at almost negligible costs. The digital business model is customer-centric, as the target market and the value dimensions offered by business models must be defined from a customer perspective. Transforming a business model into a digital one can be classified as successful if the newly formed business model changes fundamentally, especially in the following three dimensions: value creation, value delivery and value capture. It was not long before the optimism of a new decade disappeared. By the end of the first quarter of 2020, companies were spinning as they considered the effects of the COVID-19 pandemic. Unfortunately, the impact of the virus has been too great for many companies, leaving millions of workers unemployed and causing thousands of companies to close their doors. Companies that remained afloat had to act quickly to afford remote workforce and maintain operations. In 2021, there are few precedents for projecting the future. The economy is showing signs of stability, but there are persistent fears about ongoing challenges or additional surprises. Despite all the confusion, however, there are still some basic concepts that will form next year. Digital operations are more important than ever, with many transformational changes accelerating in the last year. Equitable treatment for all is an absolute mandate, making diversity, equity and inclusion an absolute priority. The influence of technology is massive, forcing new approaches to regulatory behavior. As the industry emerges from a chaotic year, a phase of reconstruction will begin, but this reconstruction is beyond restoration. There is little chance of going back to the old way of doing things. Thanks to the changes that no one would have wanted and fueled by the demands of a digital society, the technology industry will undoubtedly take a new shape in the future.

The logistics of the production and distribution of tourist and travel products can be seen as a certain industry with complex distribution chains, consisting of interdependent transport companies, accommodation facilities, attractions, catering companies, tour operators, travel agencies and recreational and leisure facility providers. Everyone in this system uses information technology in different ways for product development, business administration, marketing and market communication, sales, reservations, internal and external communication. Similarly, the tourist and the traveler, with the help of wireless networks and mobile technologies, are increasingly using information technology and digital systems in everyday life, work, leisure and travel, as well as in their consumption of goods, services and experiences. This makes the analysis of digital trends in tourism and customer behavior a complex effort and almost impossible to cover all aspects.

2020 has been a challenging year on many fronts. Tourism has endured the ongoing stress caused by the COVID-19 outbreak [10]. Experienced by all, this changed the way individuals, groups and organizations worked. It was a period full of events and unexpected changes, a very difficult and precarious situation which, seen through an optimistic lens, can bring home lessons on how to operate in uncertain and unexpected environments. The digital transformation has been the main change that the world has perceived directly and visibly. Most of the companies analyzed state that COVID-19 has accelerated the digitization process and digital communication strategy by several years [15]. But enterprises are not the only ones entering a rapid phase of transformation [26,32]. Customers, the driving force of each business sector, have also changed. The logic in which everyone works has changed. The tools and services used have migrated to the cloud. Employees were forced to immediately update their technical and digital skills, communication with customers must be personalized quickly and efficiently. It is imperative that organizational structures adapt to the requirements of this particular period. The complexity of the political environment, combined with the unique characteristics of SMEs in the field of tourism, can negatively affect the adoption of digital technologies, risk perceptions, trust. Governments can play a leading role in setting the framework conditions to support tourism business models, value chains and digital ecosystems [14]. Policy measures could include massive support for practical innovation and capacity building through incubators, accelerators, mentoring opportunities and other non-technological initiatives (tourism networks) to encourage adoption, catalyze tourism business ecosystems and promote a digital mentality [27].A policy environment that supports and enables the digital transformation of tourism firms and aims to increase productivity and innovation could include the following policy measures [2]: a) Improving access to human resources, skills and information to raise awareness of opportunities and benefits, to facilitate the adoption of digital technologies and to 
strengthen the capacity to participate in new and emerging digital ecosystems. b) Construction of data warehouses on key issues and the impact of digitization for tourism SMEs. Targeted and nuanced approaches to regulation, financing, investment and incentives should be based on a better understanding of the different needs of digital native businesses and traditional tourism businesses with low levels of digital absorption. c) Support the accessibility and affordability of digital technologies, tools and solutions for tourism SMEs, including initial investments and ongoing costs. Encourage the business model and ecosystem innovation through convergence, interoperability and the adoption of data analysis and other favorable technologies. Innovative business models are a lever for optimizing the benefits of digital transformation. Measures that help innovate business models and management practices and transform traditional work practices will complement other policy initiatives. A key objective in catalyzing digitally enhanced tourism is to encourage digital-physical convergence and to promote smart tourism goals. Specific actions could include: i) Facilitating increased access to high-speed broadband and other digital infrastructure for businesses and tourism visitors from cities, regions and rural areas, in order to benefit from the production and delivery of tourism experiences without issues, tourism management, data exchange and analysis; ii) Encouraging public-private partnerships and collaborations between traditional SMEs and native digital enterprises and educational institutions to improve the exchange of knowledge, the dissemination of expertise in the field, the development of a support recommendation system as guides to support learning processes [20, 22]; iii) Collaboration of actors with diverse and complementary experience in the field of technology, tourism and other sectors, to create a dynamic digital business environment in which both start-ups and existing tourism enterprises can coexist functionally. The ongoing digital revolution of virtual worlds and virtual reality (VR), augmented reality (AR), real and virtual world simulations and mergers opens up even more complex solutions and scenarios for digital applications and new trends in tourism [18].

\section{Analysis of the main information technologies with direct impact on TPA}

Digital technologies allow us to improve such business processes in the organization, such as interaction with suppliers, storage and transmission of information, document management, security and identification. The digitalization of business processes in tourism depends directly on the availability of professional digital skills of employees of a tourism enterprise. The digital platform manages an end-to-end business process needed to achieve an enhanced experience for customers, employees and partners. Multiple components make up a digital platform: a data ingestion engine, a transactional machine learning machine to perform rules-based activities or activities, an analytics engine and increasingly, an AI engine, APIs or tools allowing digital platforms to talk to other software programs and tools that monitor regulatory compliance. These components need to be aligned and integrated to create better user experiences. Digital platforms allow for a data-based world, rather than a process-based world. The digital platform manages an end-to-end business process needed to achieve an enhanced experience for customers, employees and partners. Digital platforms cover traditional organizational structures, silos, policies and technology investments to enable the new operating model. They force a different organization, a different talent model, a different mentality and a different set of policies and processes. Rethinking and redesigning these components of an operating model requires profound change across the organization. That amount of change and disruption often causes resistance. A digital platform can improve experiences for customers, employees and partners. Digital technologies provide opportunities for business leaders to rethink their business to create better experiences for customers, employees and ecosystem partners and to reduce costs. When companies act to take advantage of these opportunities through digital transformation, they undertake two main activities: building a digital platform and building a new operating model (business). Both activities must take place at the same time and this presents a trap: a company is limited in how far it can go in changing its operating model (business), unless the digital platform succeeds. The incorrect approach to this trap leads to the failure of many digital transformation initiatives. A digital platform can be considered as the total amount of a place for exchanges of information, goods or services between producers and consumers, as well as the community that interacts with that platform. It is imperative to understand that the simple community itself is an essential part of the digital platform and that, without this community, the digital platform has very little inherent value. We interact with digital platforms constantly due to the success of the digital platforms approach. Digital platforms take many different forms, depending on the business model they use and the specific purposes they want to serve. Digital platforms offer value to everyone in the platform ecosystem, while recording a profit for the organization that created it and maintains it through various business models, such as advertising, subscriptions, tailor-made payment or any combination of them and other methods of making a profit.

Digital transformations look different for each company, because each organization has different goals in mind, but a tangible goal to look for through digital transformation is to create a digital platform. While digital platforms are not lacking, there is still plenty of room for innovation and niche services that have audiences waiting for the day when their needs are finally met. Many digital platforms compete for similar audiences, but capitalize on their competitive advantages and unique aspects to reach their particular audience as they try to grow. Creating a digital platform will provide a competitive advantage over rivals, 
ensuring that you serve your niche with the massive value proposition not only of the services but also of your platform community. A successful digital platform facilitates exchanges or goods, services or information, while using the community itself to add value to everyone in the ecosystem. Creating a powerful digital platform that provides ease of use, reliable transactions and protection for users against the bad actors on the platform is a delicate balancing act that has the ability to provide incredible levels of success for those who can manage it.

Currently, the sale of holiday packages on the Internet is increasing by $20 \%$. The main consumers of travel services are people in generation Y (millennials) and generation $\mathrm{Z}$, for which modern digital communications are the norm. Already, $50 \%$ of requests use mobile search. The tourism needs of the new generation are changing, therefore, tour operators should customize their product for the customer, and the tour operator's website should be adaptable, able to accept card payments and other electronic payment methods. The time from search to purchase of a tourist product should be kept to a minimum. Today, many companies in the tourism industry use digital technology tools such as e-mail, document management, CRM, mobile telephony and more. Digital economy technologies make it possible to provide the most personalized interaction that most modern travelers prefer. Transforming the interaction of sellers and buyers in the tourism sector affects, among other things, global distribution systems. Today, there are already promising projects (WindingTree) based on blockchain platforms that ensure the interaction of all participants in the production process. In the future, this or similar systems have a real chance of eliminating GDS giants from the market. It is worth noting that the software of many GDS is based on relatively outdated technologies and cannot compete with modern digital platforms, which undoubtedly have advantages. For example, WindingTree offers a simplified interaction process, eliminating the need for high commission costs for additional intermediaries, ensures the uninterrupted operation of the system thanks to blockchain technology [40]. This project has already been implemented at Lufthansa Airlines, similar blockchain tools are used at the airport in Dubai, in the transport system in Japan and South Korea, etc. Tourism councils and companies in the tourism sector can benefit from big data in many ways. This includes accurately identifying marketing campaigns, offering packages tailored to the likely interests of visitors, and deciding in which countries to focus on gaining customers. This knowledge can be very helpful in the decision-making process and can improve the way the tourism industry operates. Players in the tourism industry can now make informed decisions based on analysis and number-based data. They can identify target groups of potential customers at each stage of the trip planning process. They can also increase the efficiency and quality of services. Big data can even be used to predict what new products might work well in their marketplace. For tourists, efficiently used big data technologies can be translated into personalized offers adapted to their interests and needs. They can receive enhanced experiences that focus on customers and their needs. Big data can be used not only as a predictive tool to predict future trends, but also in real time to anticipate and respond to the needs of tourists almost immediately. Many of the big data issues generally apply to the tourism sector. One of these is the difficulty of sharing information between sources. Part of this problem may be that the information is often too complex and difficult to understand. Data statistics cannot be included in action plans. Easy viewing is the key. For consumers, big data needs to focus on their experience, without making it too invasive. Protecting consumer privacy is essential.

On the other hand, with $5 \mathrm{G}$ technology, the tourism sector will become connected at every level. Whether it is transport, culture or hospitality, this new generation of wireless network will bring many improvements and technological advances. Technologies are evolving at a rapid pace. They change the daily lives of both companies and tourists. The implementation of $5 \mathrm{G}$ technology could affect the activities of several sectors of the tourism industry. Although its use by the general public is expected in just a few years, this new technology raises some questions about its potential for tourism. 5G technology will bring many changes in communications and data sharing. It will provide virtually ubiquitous connectivity. This type of network has many advantages, including: latency time due to poor network, for example, is considerably reduced and data transmission will be ten times faster than $4 \mathrm{G}$ technology; reducing waiting times: the communication time between two devices can be up to one millisecond; connection density: more devices can be connected per square kilometer, about one million, compared to 2000 with 4G technology; Energy efficiency: the battery life of phones is significantly increased, as it is now the network that manages much of the data. For some technologies used in tourism, such as virtual and augmented realities, the new network uses higher bandwidth. Reduced latency improves content, in addition to synchronizing between participant movements and visual perception. The experience will become much more captivating. Speed, transferable amount of data and decreased response time will also have an impact on artificial intelligence. Information processing and response of machines or applications that use this technology will be more efficient. 5G technology also allows for the widespread deployment of things in virtual space, as it provides an opportunity to connect multiple devices at the same time and increase the speed of exchanges. This new generation of wireless network will increase punctuality and security in airports, stations, etc. Passenger information will thus become more accurate and will be transmitted over time. 5G technology will have a significant impact on self-driving vehicles, which will be safer and more autonomous. The integration of technology in hotels has become essential to provide unique customer experiences. Whether it's connected cameras, voice assistants, 
chatbots etc., these units will be much more efficient due to $5 \mathrm{G}$ technology and the improvements it brings to $\mathrm{AI}$ and the Internet of Things (IoT). Many hotel chains are currently considering integrating this technology to provide innovative and personalized services.

Using virtual and augmented reality during an event will be very efficient, due to the increase in bandwidth and the reduction of latency time. 5G technology will reduce the need for Wi-Fi, simplify and improve online content delivery and live interactions during conferences. At indoor or outdoor meetings, telephone networks will become less crowded, to the delight of participants, who will no longer have difficulty interacting and posting photos of the event on social networks. 5G technology will make cultural experiences more attractive, due in part to advances in virtual and augmented reality. In addition to visitor activities, this technology will bring some benefits to museums. The potential for digitization and virtual storage of cultural values will be developed, and robotics will support the work of curators. For example, an arm of a remote-controlled robot restored an art object with great precision [25, 35]. IoT is a part of the future digital ecosystem that will have a significant impact on the development of e-tourism services. Location and geographical services have become a new area of rapid business development. These services play a key role in the development of IoT scenarios, smart spaces and proactive solutions. Smart tourism is one of the most fascinating fields of application. In many cities, various social problems, such as insecurity, fraud and lack of adequate information on resources, are the biggest obstacles to tourism. Smart tourism design can help travelers capture and process all the data that involves users, turning them not only into useful information, but also into personalized knowledge. The system is designed to develop the tourism industry so as to attract different groups of customers and offer users new and ideal communication, information and entertainment applications and services in a new business model. Depending on the needs of cloud-based services, new ways to search for travel information can be developed. Using smartphones, global positioning systems (GPS), Google Maps, augmented reality (AR) and global interoperability for microwave access networks (WiMAX), mobile users are being offered a whole new travel experience. The development direction and prospects of $5 \mathrm{G}$ smart tourism are very optimistic. The integration of $5 \mathrm{G}$ technology in the field of tourism and its combination with $\mathrm{AR}, \mathrm{AI}$, social sharing and other applications, while benefiting from its functions of high speed, high bandwidth and low latency, will give rise to a smart upgrade tourist attraction. Promoting the application and development of 5G smart tourism is an important area, such as the regional economy, as well as increasing employment opportunities. It can play an important role in promoting mutual understanding.

In competitive environments, the ability to influence the choice of hotels is becoming increasingly important, with many international chains fighting each other by increasing their loyalty programs. These customer rewards are made through hotel points, credit cards and partnerships with airlines for wider coverage. Using data provided by guests, the hotel industry has actively explored the implementation of Business Intelligence (BI) programs, which are a competitive advantage for hotels and travel agencies. While many IT tools can be easily imitated and reproduced, BI systems can be used methodically to gain a sustained competitive advantage over industry competitors. These systems can provide a competitive advantage to companies that feel high competitive pressure, for example, common in urban centers. All of these systems can be simpler or more complex, depending on the type of business, but they always generate useful information about guests. Today, BI systems are accessible to everyone. BI systems allow hotel units a systematic analysis, by collecting statistical data and intensive processing of data obtained a real advantage among competitors. This data through the OLAP and Data Mining systems allows the understanding of behavior patterns and helps in targeting the target audience. This tool is extremely important as it helps administrations and financial management to make decisions based on qualified scientific data.

Cloud computing migration is one of the current challenges for businesses. This technology offers a new "pay-as-you-go" paradigm for information and communication technologies. In this sense, it is assumed that the small and medium enterprise is the most interested, because the initial investments are avoided and the technology allows the gradual implementation. Organizations are more focused on adopting cloud-based services to increase their computing and processing power with reduced operational and maintenance costs. To survive today's competitive business landscape, businesses need to focus on analytics to improve productivity and efficiency. Companies that make value-based decisions are much more successful at gaining value from the internet-connected environment than those that still use traditional methods. Focusing on IoT involves the transformation, collection, and special study of data and the clear interpretation of various information. The transformation should take place throughout the organization, including technology, personnel, and operations. Large volumes of data should be obtained and studied by specialists for best results. Using a team of scientists, analysts and business executives is the safest strategy. The key is to combine internet-connected analysis with other data provided by businesses (CRM, sales), public data (weather, public census) and data from third parties (demographics). The tourism industry is a sector where service providers need to collect real-time feedback and respond quickly, in the best possible way. Service providers can deploy IoT in travel to collect real-time feedback. The transformative role of IoT in travel The travel industry is a collection of several services provided by various subsectors, such as aviation, cruises, hotels and restaurants, where a bad experience even a small one can impact the entire trip. IoT can help you 
connect all these sectors together to provide travelers with a satisfying overall experience. IoT can also help monitor the health of passengers on flights. For example, seats with built-in sensors can monitor and keep track of vital aspects of passengers. These sensors can send automatic alerts to the flight crew in case of unusual vital levels to avoid any medical accident during the flight. Airlines can use IoT devices to frequently monitor internal systems or flight components. For example, IoT sensors can monitor engine performance and send proactive alerts to maintenance administrators. Proactive maintenance helps prevent system failures. Most travelers stay at hotels and during peak holiday periods, the burden on hotel staff to provide customers with the best customer service increases. Using IoT in hotels helps provide personalized rooms to guests. Customers can connect their smartphones or tablets to the sensors in the hotel room. Then they can control all the devices with the help of their smartphones. Adjusting the room temperature, lighting and ordering food on their smartphones become possible thanks to IoT. Integration with mobile devices also allows hotel managers to save a customer's preferences for future travel. Hotel staff can also use the IoT. The installed rooms can detect the presence of any person in the hotel rooms and can alert staff members whenever a room is empty. Staff can clean the rooms when they are empty to provide guests with comfortable experiences. IoT can also be used by hotel administrators to save costs. The sensors can automatically adjust the room lights based on the sunlight in the rooms. They can also detect room occupancy to automatically adjust the temperature of the air conditioner without compromising guest comfort. Cruises are one of the most fascinating ways to travel if travelers are surrounded by water and landless. Cruise ships can carry thousands of people at once, and providing such a large number of services is always a daunting task for the crew. With IoT the cruise crew can easily provide services for thousands of travelers.

Another fascinating thing that can be made possible with IoT museums is an audio description of the art or monument. When a person is near a monument, the beacons can connect to his smartphone. The person can then hear an audio description of the monument. We often come across news about taxi drivers who deceive tourists by taking extra charges or taking them on longer routes than necessary to increase the fare. This can have a negative impact on the overall experience of travelers, which, if seen as a consistent model, can reduce tourism in a country. Governments can play a vital role in eliminating such cases of exploitation by improving public transport services. Governments can benefit from IoT while traveling to reshape public transportation.

Facial recognition technology is also being explored and used more often in the tourism industry. It can be especially useful here, because travel companies have to deal with a large number of passengers and customers, so any technology that can help speed up processes is extremely beneficial. In addition, in airports and hotels, security is a key concern, and facial recognition can be used to make it easier to identify people, to give certain people access to places, and to keep others out of them. Moreover, the ability to recognize faces almost instantly can also improve the customer experience through greater personalization. For hotels and other companies in the tourism industry, data plays a crucial role in enabling them to provide excellent services and optimize their processes. This is an area where facial recognition technology is likely to play a more critical role in the next few years, enabling automatic data collection. Instead of simply matching faces in an image with faces in a database, technology can also be used to identify gender characteristics, provide an estimate of their age, and determine their status spirit. This can then provide reliable information about customer demographics and how they respond to different locations and services, with businesses using this to pick important trends. Airport security checks take a long time. Therefore, passengers must arrive at the airport hours before flight hours. With the help of biometrics, IoT can reduce the time spent on airport security checks. Airport cameras can scan the faces of airport passengers and send data to servers where deep learning algorithms can match the face image to verify a person's identity. Rooms at each checkpoint, such as the boarding gate, can reduce the total check-in time at the airport. Facial recognition technology is already being used to provide faster security, departure and arrival services. Although the rate of mishandling has dropped sharply, millions of bags are still mishandled at airports each year. This is where IoT tags and RFID tags come into play. Beacons can automatically detect and track RFID tags attached to bags without any human intervention. Airport passengers and officers can receive real-time notifications on their mobile devices about the location of bags to prevent mishandling.

\section{Conclusions}

Tourism has become one of the fastest growing economic sectors in recent years, with the exception of 2020, for objective reasons. Needless to say, the tourism industry needs to be up to date and apply the latest technologies. At the same time, the significant development of information technologies, especially cloud-based ones, introduces a new paradigm - intelligence in all spheres of human life. From a tourism perspective, the combination of cloud computing, human cooperation and Internet-of-things technologies can improve the efficiency of tourism resource management and provide what can be called a smart tourist destination. In addition, it allows tourism organizations to use the cloud as a key resource, as a management system that holds large amounts of data that provide a geographic information service. This allows companies to interact with their consumers in a two-way process that enables B2C through the cloud. Some of these are developed for end users as web-based software, such as remote notebooks. Others are 
implemented as web services that interact with requesting agents, such as weather forecasting services and also web translation services. Cloud computing also helps address one of the weaknesses of using mobile systems, creating greater accessibility to managing travel destinations and also engaging B2C anywhere. Cloud allows the delegation of processing and storage tasks for tourism organizations that were previously owned by other platforms with limited capacity. Therefore, it allows the tourist to have access to a higher level of information from the cloud. Cloud computing is based on established trends that have already given IT platforms a new shape over the years. But with cloud computing, we get additional cost advantages, faster deployment, high efficiency, less complexity, lower administration requirements and efficient capacity management and all this proves to be an advantage for today's IT industry, everyone looking for these advantages in business and service delivery. What must be remembered is that tourists are unique in that their activities are extremely constrained by the space-time budget. Virtualization adds to hardware flexibility and makes software deployments and redistributions easier and more efficient without actually being connected to a specific physical server. This makes the data center more dynamic, where resources can be implemented and evaluated more efficiently. This efficiency also has a positive effect and ensures the optimal use of storage and network resources to meet technical and business requirements in a cost-effective way. As the implementation of an application becomes independent of the server deployment factors, it becomes more scalable. Virtual machines have become common and widespread deployment units and result in minimal administrative complexity among service providers and developers, while adding scalability benefits and more flexibility. This is combined with the fact that, by managing the cloud platform, hardware resources can be integrated. Any revenue manager with experience in the field of tourism knows that in recent years, internal revenue management and digital marketing have changed in close connection with the most important information technologies. It is now about an effective digital channel distribution strategy. We cannot be responsible only for the implementation of the processes, but we must make sure that we fill the hotels with the most profitable guests. This has only become a reality if we have implemented an organizational strategy and a revenue optimization culture. The sales, marketing, finance and revenue management department must be perfectly regulated, only in this way will it be possible to generate a higher return on investment than our competitors. However, the lack of knowledge about consumer behavior in digital environments in hotels is remarkable and many professionals still do not understand its real significance. Each revenue management implementation must be followed by a technological mix applicable to each reality of the company, professionals can provide meaningful answers to revenue, fulfilling the wishes of all administrations, while they ensure their jobs. These professionals must have freedom of action and do their job properly, always taking into account the best performance of total income. They must be properly trained and know all the processes that lead to value creation within business units. In the tourism and hotel sector, technological systems are more important in revenue production and business performance. However, there is a profound lack of knowledge about IT systems and consumer behavior in digital environments.

\section{References}

1. Baralla G, Ibba S, Marchesi M, Tonelli R, Missineo $S$ (2018) A blockchain based system to ensure transparency and reliability in food supply chain. In: European conference on parallelprocessing. Springer, Cham, pp 379-391

2. Calbimonte JP, Martin S, Calvaresi D, Zappelaz N, Cotting A (2020) Semantic data models for hiking trail difficulty assessment. In: Neidhardt J, Wörndl W (eds) Information and communication technologies in tourism 2020, pp 295-306. Springer, Cham

3. Christina Lohvynenko, Dietmar Nedbal, (2019) Usage of Semantic Web in Austrian Regional Tourism Organizations https://link.springer.com/chapter/10.1007/978-3-030-33220-4_1

4. Ciftci O, Choi EK, Berezina K (2020) Customer intention to use facial recognition technology at quick-service restaurants. E-rev Tour Res 17(5):753-763

5. Dacrema Ferrari M, Cremonesi P, Jannach D (2019) Are we really making much progress? a worrying analysis of recent neural recommendation approaches. In: Proceedings of the 13th ACM Conference on Recommender Systems, pp 101-109. RecSys '19, Association for Computing Machinery, New York

6. Dapp MM (2019) Toward a sustainable circular economy powered by community-based incentive systems. In: Business transformation through blockchain. Palgrave Macmillan, Cham, pp 153-181

7. Davenport T, Guha A, Grewal D et al (2020) How artificial intelligence will change the future of marketing. J Acad Mark Sci 48:24-42

8. Dogru T, Mody M, Leonardi C (2018) Blockchain technology \& its implications for the hospitality industry. Boston University

9. Gretzel U, Werthner H, Koo C, Lamsfus C (2015) Conceptual foundations for understanding smart tourism ecosystems. Comput Hum Behav 50:558-563. https://doi.org/10.1016/j.chb.2015.03.043

10. Gretzel U, Fuchs M, Baggio R, Hoepken W, Law R, Neidhardt J, Pesonen J, Zanker M, Xiang Z (2020) e-Tourism beyond COVID-19: a call for transformative research. Inf Technol Tourism 22(2):187-203. https://doi.org/10.1007/s40558-020-00181-3

11. Hashim NL, Isse AJ (2019) Usability evaluation metrics of tourism mobile applications. J Softw Eng Appl 12(7):267-27717

12. Hosseini $S$ (2020) Using a chatbot to increase tourists' engagement. LAB Universityof Applied Sciences

13. Ivanov SH, Webster C (2017) Adoption of robots, artificial intelligence and service automation by travel, tourism and hospitality companies-a cost-benefit analysis. Artificial Intelligence and Service Automation by Travel, Tourism and Hospitality Companies-A CostBenefit Analysis

14. Leung XY, Xue L, Wen H (2019) Framing the sharing economy: toward a sustainable ecosystem. Tour Manag 71:44-53

15. Lippi G, Plebani M (2020) The novel coronavirus (2019-nCoV) outbreak: think the unthinkable and be prepared to face the challenge. Diagnosis 7(2):79-81. https://doi.org/10.1515/dx-2020-0015

16. Lukanova G, Ilieva G (2019) Robots, artificial intelligence, and service automation in hotels. Robots, Artificial Intelligence, and Service Automation in Travel,Tourism and Hospitality, pp 157-183. Emerald Publishing Limited 
17. Lombardi M, Pascale F, Santaniello D (2019) An application for cultural heritage using a chatbot. In: 2019 2nd international conference on computer applications and information security (ICCAIS), pp 1-5. IEEE

18. Loureiro SMC, Guerreiro J, Ali F (2020) 20 years of research on virtual reality and augmented reality in tourism context: a text-mining approach. Tour Manag 77:104028. https://doi.org/10.1016/j.tourman.2019.104028

19. Mariani M, Baggio R, Fuchs M, Höepken W (2018) Business intelligence and big data in hospitality and tourism: a systematic literature review. Int J Contemp Hosp Manage 30(12):3514-3554. https://doi.org/10.1108/IJCHM-07-2017-0461

20. Massimo D, Ricci F (2018) Harnessing a generalised user behaviour model for next-POI recommendation. In: Proceedings of the 12th ACM conference on recommender systems, RecSys 2018, Vancouver, BC, Canada, October 2-7, 2018, pp 402-406

21. Mao Z, Lyu J (2017) Why travelers use Airbnb again? Int J Contemp Hosp Manag 29(9):2464-2482

22. Massimo D, Ricci F (2020) Enhancing travel experience leveraging on-line and off-line users' behaviour data. In: IUI '20: 25th international conference on intelligent user interfaces, Cagliari, Italy, March 17-20, 2020, Companion, pp 65-66. ACM

23. Mende M, Scott ML, van Doorn J, Grewal D, Shanks I (2019) Service robots rising: how humanoid robots influence service experiences and food consumption. J Mark Res 56(4):535-556

24. Ozdemir AI, Ar IM, Erol I (2019) Assessment of blockchain applications in travel and tourism industry. Qual Quant 54:1-15

25. Paluch S, Wirtz J (2020) Artificial intelligence and robots in the service encounter. J Serv Manage Res 4(1):3-8

26. Pan SY, Gao M, Kim H, Shah KJ, Pei SL, Chiang PC (2018) Advances and challenges in sustainable tourism toward a green economy. Sci Total Environ 635:452-469

27. Pohjola T, Lemmetyinen A, Dimitrovski D (2020) Value co-creation in dynamic networks and e-tourism. In: Xiang Z, Fuchs M, Gretzel U, Höpken W (eds) Handbook of e-tourism. Springer, Cham, pp 1-23

28. Reinhold S, Zach FJ, Krizaj D (2017) Business models in tourism: a review and research agenda. Tour Rev 72(4):462-482. https://doi.org/10.1108/TR-05-2017-0094

29. Rhee CE, Choi J (2020) Effects of personalization and social role in voice shopping: an experimental study on product recommendation by a conversational voice agent. ComputHum Behav 109(106359)

30. Riasanow T, Jäntgen L, Hermes S, Böhm M, Krcmar H (2020) Core, intertwined, and ecosystem-specific clusters in platform ecosystems: analyzing similarities in the digital transformation of the automotive, blockchain, financial, insurance and IIoT industry. Electronic Markets. https://doi.org/10.1007/s12525-020-00407-6

31. Samala N, Katkam BS, Bellamkonda RS, Rodriguez RV (2020) Impact of AI and robotics in the tourism sector: a critical insight. J Tour Futur (ahead-of-print)

32. Santos MC, Veiga C, Águas P, Santos JAC (2019) Sustainability communication in hospitality in peripheral tourist destinations. Worldwide Hospital Tour Themes 11(6):660-676

33. Skilton M., Hovsepian F., (2018) The 4th industrial revolution: responding to the impact of artificial intelligence on business. Palgrave Macmillan, Switzerland

34. Stylos N, Zwiegelaar J (2019) Big data as a game changer: how does it shape business intelligence within a tourism and hospitality industry context? In: Sigala M, Rahimi R, Thelwall M (eds) Big data and innovation in tourism, travel, and hospitality. managerial approaches, techniques, and applications. Springer, Singapore, pp 163-181

35. Tussyadiah I (2020) A review of research into automation in tourism: launching the annals of tourism research curated collection on artificial intelligence and robotics in tourism. AnnTour Res 81:1-315.

36. Ulrike Gretzel, et al. (2020) e-Tourism Beyond COVID-19: A Call for Transformative Research https://www.researchgate.net/publication/341744907_e-Tourism_beyond_COVID-19_a_call_for_transformative_research

37. Ukpabi DC, Aslam B, Karjaluoto H (2019) Chatbot adoption in tourism services: A conceptual exploration. Robots, Artificial In telligence, and Service Automation in Travel, Tourism and Hospitality, pp 105-121. Emerald Publishing Limited

38. Um T, Chung N (2019) Does smart tourism technology matter? lessons from three smart tourism cities in South Korea. Asia Pac J Tour Res 1-19

39. Volchek $K$, Law $R$, Buhalis D, Song H (2020) Exploring ways to improve personalisation: the influence of tourist context on service perception. E-review Tour Res 17(5):737-752

40. https://www.phocuswire.com/hahn-air-winding-tree-blockchain-air-ticket 